\title{
Learning Object Systems and Strategy: A Description and Discussion
}

\author{
Albert D. Ritzhaupt \\ School of Teaching and Learning, College of Education, \\ University of Florida, Gainesville, FL, USA
}

\section{aritzhaupt@gmail.com}

\begin{abstract}
This paper provides a rich discussion on the history, definition, application, and evolution of learning object systems. A learning object is "any digital resource that can be reused to support learning" (Wiley, 2000). Learning object systems are based on the notion that multiple educational institutions could share the use and cost of the creation and management of the learning objects. The theoretical result of sharing learning objects leads to a much lower cost per educational institution. Learning objects are based on the generative and constructive learning theories that assert that learning is an active process of constructing rather than acquiring knowledge, and instruction is a process of supporting that construction rather than communicating knowledge. Learning objects are also based on sound design principles of the object-oriented paradigm. These combined theories provide a framework for learning object systems as: accessible, reusable, interoperable, adaptable, granular, versionable, cohesive, and loosely coupled. This paper will expand on these topics and provide two cases of learning object systems implemented as eLearning strategies. Closing remarks and implications are provided.
\end{abstract}

Keywords: eLearning Strategy, Learning Object, Learning Object Repository, Learning Object Metadata, Learning Object Interoperability, Learning Object System.

\section{Introduction}

\section{History of Learning Objects}

Less than thirty years ago, computers were mainly used in the areas of business, science, and engineering. The notion of personal computing was still very distant and unlikely - at best a rarity. Today, life without personal computing is the rarity, and the breadth of personal computing has expanded to include education, entertainment, information science, and communication. Computers, the Internet, and other various technologies promise significant improvements in the delivery of quality enhanced education. However, it is fulfilling this promise that is not always

Material published as part of this publication, either on-line or in print, is copyrighted by the Informing Science Institute. Permission to make digital or paper copy of part or all of these works for personal or classroom use is granted without fee provided that the copies are not made or distributed for profit or commercial advantage AND that copies 1) bear this notice in full and 2) give the full citation on the first page. It is permissible to abstract these works so long as credit is given. To copy in all other cases or to republish or to post on a server or to redistribute to lists requires specific permission and payment of a fee. Contact HPublisher@InformingScience.orgH to request redistribution permission. easy.

Technology-enhanced education is hardly a new idea in the midst of the information age. It covers a wide range of possibilities - from the use of an overhead projector in the classroom to comprehensive courses fully facilitated over the Internet. With the explosive changes in technology, educators are faced with the challenge of learning and 
effectively exploiting the available technologies. The theme of this paper is discussing a newer development of technology-enhanced known as learning objects. Learning objects are elements of an approach to technology-enhanced education grounded in the principles of the object-oriented paradigm in computer science and instructional technology in education (Wiley, 2000).

It is very difficult to determine who coined the term learning object and when this occurred, but established credit is given to Wayne Hodgins, a learning and information futurist (Hodgins, 2002). The story says Hodgins was watching his children build things out of Legos while thinking about learning strategies. Wayne experienced an epiphany realizing that the world needed building blocks for interoperable pieces of learning - namely learning objects.

However, the Lego analogy, as explained by David Wiley, is an incomplete analogy in describing the inherent structure and nature of a learning object. The problem with the metaphor is the innate properties of Legos: (1) any Lego block is combinable with any other Lego block, (2) Lego blocks can be assembled in any manner one chooses, and (3) Lego are so simple and fun that even children can assemble them (Wiley, 2000). The presumptuous nature of this metaphor might lead one to believe that learning objects also have these properties. Wiley (2000) suggests that a system of learning objects with these properties is no more instructionally useful than Lego themselves.

Instead, Wiley (2000) presents a more holistic and complete analogy - an atom. An atom is a small component that can be combined and recombined with other atoms to form a larger whole. However, atoms differ themselves from Lego in that: (1) not every atom can be combined with another, (2) atoms can only be assembled into certain prescribed structures, and (3) some understanding is a requisite to assembling atoms (Wiley, 2000). Although the differences between these characteristics of the analogies seem trivial, the implications of the differences are significant in understanding learning objects. This analogy better serves the notion of a learning object for pedagogical purposes.

\section{A Working Definition for Learning Objects}

The term learning object surfaced more than fifteen years ago in a paper written by Hodgins, and since then has evolved into many different forms depending on the source. Unfortunately, understanding a learning object is not as difficult as defining it. Since the concept of a learning object is still a relatively new idea, a definition of a learning object is first provided to better describe what a learning object is and what it is not.

A learning object, as defined by the Institute of Electrical and Electronics Engineer's (IEEE) Learning Technology Standards Committee, "is any entity, digital or non-digital that can be used, re-used or referenced during technology supported learning" (IEEE, 2002). This definition is intended to include any form of instructional material that can be used during "technology supported learning." The IEEE definition is purposefully broad to include references to non-digital books, audio, periodicals, et cetera. For example, this definition would include non-digital educational transparencies placed on an overhead projector during instruction, and digital audio clips explaining an educational concept since both could be referenced during "technology supported learning."

The problem with this working definition is not what it includes, but what is fails to exclude. It fails to exclude any noun that has ever existed in the history of mankind since it could be referenced during "technology supported learning" (Wiley, 2000). For instance, the definition would fail to exclude World War II since it could be referenced during "technology supported learning." To narrow down the range of possibilities, the definition, as defined by David Wiley, is "any digital resource that can be reused to support learning." The range of possibility is now limited to include only digital entities, such as digital images, video feeds, animations, or perhaps web appli- 
cations being used to "support" learning. Using this definition, it is easier to trace the use of learning objects to incorporate an e-learning strategy since the learning objects themselves are digital in nature and accessible over the Internet.

\section{Learning Objects Awareness and Impact on Organizations}

Since the inception of the term learning objects, many different groups have started working in this area. The IEEE formed the Learning Technology Standards Committee to be on the forefront of development standards (IEEE, 2002). The IMS Global Learning Consortium, a non-profit organization, was formed to develop and promote the adoption of open technical specifications for interoperable learning technology (IMS, 2003). Even Oracle did some early work that later developed into Oracle Learning Application. Although the Oracle Learning Application never came to fruition, it did contribute to the culmination of future standards and technical innovations.

The United States (US) Federal Government is the world's largest training organization, so it also has a critical role to play in the use of learning objects both in terms of being the largest "customer" and the direction of learning objects (Learnativity, 2004). A satellite broadcast had top officials from the White House, the Department of Defense and the Department of Labor, to name a few, who are working in this area. Hodgins, as a panelist, took advantage of the opportunity after the broadcast to discuss with the federal people the need for some common understanding and directions relative to their mutual interests in learning objects (Learnativity, 2004). Hodgins subsequently met with them to organize a meeting for top level US Federal Government officials to drive a common understanding of the work being done in this area and how they can all work best to move forward.

Steven Downes, a research scientist specializing in online design and research, argues that the major benefit provided by learning objects to organizations can be reduced down to simple economics (Downes, 2003). His conviction, however, is based on a few realistic assumptions.

Assumption: There are thousands of universities and colleges that teach introductory statistics, and part of this course generally requires a discussion on conditional probability.

Assumption: Although the instructor and textbook of this course may differ from institution to institution, the properties and equations of conditional probability stay the same. Therefore, there are thousands of similar descriptions of conditional probability.

Assertion: The education systems do not need thousands of similar descriptions of conditional probability. Instead, education systems need perhaps a dozen descriptions to suit the needs of individuals with different learning styles.

Therefore, multiple institutions could share the use and cost of the creation and management of the learning objects. It does not make financial sense to spend millions of dollars producing multiple versions of similar learning objects when single versions of the same objects could be shared at a much lower cost per institution (Downes, 2003). Downes argues that there must be sharing, because no institution producing its own materials on its own could compete with institutions sharing learning materials.

The need for learning objects makes more than just economic sense. From a state-wide university standpoint, learning objects could help with: the inconsistencies and perceived duplication among courses and programs with the same titles, and in some cases, the same numbering; the difficulty in getting courses into the online arena, both from a development standpoint and from the perspective of how to manage and deliver such courses; the variability of technology from campus to campus, and as a result, variability of access for both students and faculty; and the competition among varying educational institutions and funding (Chitwood, May, Bunnow, \& Langan, 2000). 


\section{The Need for Learning Objects}

The need for learning objects is evident in the information age. Online instructional content can be shared to effectively reduce the costs of education. However, an important consideration is: How do learning objects improve the delivery of quality education? The primary purpose of this paper is to address this question. However, as the discussion will reveal, learning objects alone are not sufficient to realize this improvement.

Learning objects should be thought of as cogs in a much larger machine that, when thoughtfully constructed, sequenced, and managed, potentially result in the improved delivery of quality education. Therefore, learning objects themselves do not result in any improvements to education. The learning objects system is what results these improvements. A learning object system is a framework used to create and deliver learning experiences that support the educational needs of stakeholders. Therefore, the approach to addressing the research problem is to describe learning object systems that can be tailored to suit the needs of a variety of organizations.

This approach to address the research problem can be decomposed into finite parts. The operative terms in this problem are learning objects, improve, delivery, and quality education. The first part of the problem is to address learning objects themselves and how the design of a learning object system maps to sound instructional and software engineering theory. The second part of the problem requires a discussion on how learning object systems "improve" the "delivery" of quality education. Therefore, the learning object system is the mechanism that delivers learning objects or "quality education."

This requires a discussion of the stakeholders in a learning object system and the roles these stakeholders play and an in-depth discussion on the design and implementation of learning object systems and the benefits or drawbacks drawn from such systems. The final step is to discuss the overall learning object system as an e-learning strategy. The "how" in how learning objects improve the delivery of quality education is therefore expressed by discussing how a learning object system delivers learning objects to its stakeholders and the benefits derived from its utilization.

\section{Theoretical Framework}

This section provides a theoretical framework for learning objects and learning object systems so that the theoretical principles can be later mapped to learning object systems. It is understood that learning object systems that are designed with sound instructional principles lead to robust learning environments.

\section{Constructivist Theory}

Bannan-Ritland, Dabbagh, and Murphy (2002) suggest that there are alternative theoretical foundations other than a traditional instructional systems design perspective that can be applied to learning object systems based on constructivist and generativist philosophy of learning. Constructivism is an educational philosophy or perspective that encompasses a wide variety of views, and theories. Duffy and Cunningham believe that the constructivist philosophies and theories converge on two primary principles: (1) that learning is an active process of constructing rather than acquiring knowledge; and (2) instruction is a process of supporting that construction rather than communicating knowledge (Duffy \& Cunningham, 1996).

Constructivists believe that a learner individually interprets his or her experience by building a unique internal representation of knowledge. Generally, constructivism holds that learning outcomes are largely based on the learners, and that learners are required to actively participate in the learning process to construct meaningful knowledge rather than acquire a predetermined set 
of skills in a pre-specified manner (Bannan-Ritland et al, 2002). Bannan-Ritland et al. suggest that to incorporate constructivist principles, a learning objects system must generally be:

- Accessible - Since learning objects can be understood as digital entities they can be shared and distributed over the Internet. However, the digital definition is not enough to make learning object prevalent and accessible. The ability to search, identify, access, and retrieve learning objects is also necessary (Degen, 2001).

- Reusable - Learning objects must exhibit flexibility in order to reuse learning objects for multiple purposes, in different applications, in different products, in different learning contexts, using varying devices, for numerous markets (Degen, 2001). If learning objects are designed to be used in multiple contexts, then they can be reused easily rather than having to recreate material that has to be rewritten for each new context.

- Interoperable - A major tenet of learning object theory is the ability to use content developed by one organization on a given platform with one set of tools at a completely different organization on a different platform with another set of tools (Degen, 2001). The interoperable notion is imperative for learning objects to be useful, accessible, and reusable by other organizations.

- Adaptable - Learning objects should be able to be sequenced in a way that they can adapt to a learners needs - namely prescriptive learning. Since not all learners are the same, learning objects must be adaptable to suit the needs of learners with varying educational needs.

Bannan-Ritland et al. (2002) state that the computer environment should not be providing the knowledge and intelligence to guide learning. It should be providing the facilitating structure and tools that enable students to make maximum use of their own intelligence and knowledge - a constructivist strategy.

\section{Generative Theory}

The generative learning model, analogous to the constructivist theory, is that the learner is not a passive recipient of information, but an active participant in the instructional experience, constructing knowledge through relating information in the instructional environment to his or her previous experiences and prior knowledge (Grabowski, 1996). Bannan-Ritland et al. (2002) suggest the generative learning process requires the learner to manipulate, interpret, organize or in some active manner make sense of his or her environment. The learner then creates meaning through generative associations between and among elements in the instructional environment and his or her knowledge base. The primary element is presenting the opportunity to construct new meaning from the learner's interaction with the instructional environment and understanding of specific content. Bannan-Ritland et al. (2002) argue that to incorporate generativist principles, a learning object system must generally allow:

- Versioning - The learning object system should allow for designed and created artifacts that permit multiple versions of objects to be incorporated into the system. This would require the incorporation of an archival process to clear the repository of unwanted and outdated contributions.

- Granularity - The learning object system should allow for learner-produced artifacts to be generated on different prescribed levels or according to levels in the taxonomy of learning object types (Wiley, 2000) and tagged according to standards to allow further discovery, retrieval, and manipulation. 
Bannan-Ritland et al. (2002) propose that learning object systems should be able to be configured as generative learning environments in addition to instructional delivery systems. The flexible and dynamic nature of this type of learning object system aligns well with a generative, constructivist pedagogical approach to learning.

\section{Learning Object in the Object-Oriented Paradigm}

Software engineering is concerned with the design, development, and maintenance of large complex software systems (Boyle, 2002). If a learning object system is understood as a large complex software system, than the principles of software engineering can be traced to the design, development, and maintenance of a learning object system. Thought-leaders of learning objects have rooted learning objects in the object-oriented paradigm, which is often associated with software engineering. The object-oriented paradigm is a software development concept that focuses on the behavioral and structural characteristics of entities. The principles of software engineering and particularly the object-oriented paradigm can then be applied to learning objects.

The principle of cohesion suggests that each unit should be one thing and only one thing (Boyle, 2002). Boyle argues that a direct link can be made to the notion of learning objectives in pedagogical terms. This mapping implies that each learning object should be traced to a clear learning objective or goal. The notion of cohesion beckons another important characteristic - minimized coupling. This principle states that the unit should have minimal bindings to other units (Boyle, 2002). With respect to learning objects, this means that the content of one learning object should not refer to and use material in another learning object in such a way to create unnecessary dependencies. Boyle (2002) suggests that this principle is paramount for reusability. Thus, from a software engineering perspective, the challenge of designing a learning object is creating a highly cohesive, loosely coupled, and richly pedagogical unit.

\section{Learning Object Taxonomy}

All learning objects have particular qualities. The difference among learning objects is in the degree to which they exhibit these qualities (Wiley, 2000). Wiley (2000) presents a model taxonomy that differentiates between five learning object types. Definitions of these five object types are given below, followed by the taxonomy and characteristics, which shows their differences and similarities:

- Fundamental - An individual digital resource uncombined with any other, the fundamental learning object is generally a visual aid that serves an exhibit.

- Combined-closed - A small number of digital resources combined at design time by the learning object's creator, whose constituent learning objects are not individually accessible for reuse from the Combined-closed learning object itself. A video clip exemplifies this definition, as still images and an audio track are combined in a manner, which renders these constituent pieces unrecoverable. Combined-closed learning objects are generally single purpose, that is, they provide either instruction or practice.

- Combined-open - A larger number of digital resources combined by a computer in realtime when a request for the object is made, whose constituent learning objects are directly accessible for reuse from the Combined-open object. A web page exemplifies this definition, as its component images, video clips, text, and other media exist in reusable format and are combined into a learning object at request-time. Combined-open learning objects frequently combine related instructional and practice-providing Combined-closed and Fundamental objects in order to create a complete instructional unit. 
- Generative-presentation - Logic and structure for combining or generating and combining lower-level learning objects. Generative-presentation learning objects can either draw on network-accessible objects and combine them, or generate objects and combine them to create presentations for use in reference, instruction, practice, and testing. While Generative-presentation learning objects have high intra-contextual reusability, they have relatively low inter-contextual reusability.

- Generative-instructional - Logic and structure for combining learning objects and evaluating student interactions with those combinations, created to support the instantiation of abstract instructional strategies. The transaction shells of Merrill's Instructional Transaction Theory (Merrill, 1999) would be classified as Generative-instructional learning objects. The Generative-instructional learning object is high in both intra-contextual and inter-contextual reusability.

Table 1. Learning object taxonomy matrix (Wiley, 2000).

\begin{tabular}{|c|c|c|c|c|c|}
\hline Learning Object & Fundamental & Combined-closed & Combined-open & $\begin{array}{c}\text { Generative- } \\
\text { presentation }\end{array}$ & $\begin{array}{c}\text { Generative- } \\
\text { instructional }\end{array}$ \\
\hline \multicolumn{6}{|l|}{ Characteristic } \\
\hline $\begin{array}{l}\text { Number of elements } \\
\text { combined }\end{array}$ & One & Few & Many & Few - Many & Few - Many \\
\hline $\begin{array}{l}\text { Type of objects con- } \\
\text { tained }\end{array}$ & Single & Single, Combined-closed & All & $\begin{array}{l}\text { Single, Combined- } \\
\text { closed }\end{array}$ & $\begin{array}{l}\text { Single, Combined- } \\
\text { closed, Generative- } \\
\text { presentation }\end{array}$ \\
\hline Reusable components & (Not applicable) & No & Yes & Yes / No & Yes / No \\
\hline $\begin{array}{l}\text { Common } \\
\text { function }\end{array}$ & Exhibit, display & $\begin{array}{l}\text { Pre-designed instruction } \\
\text { or practice }\end{array}$ & $\begin{array}{l}\text { Pre-designed instruc- } \\
\text { tion and / or practice }\end{array}$ & Exhibit, display & $\begin{array}{c}\text { Computer-generated } \\
\text { instruction and / or } \\
\text { practice }\end{array}$ \\
\hline $\begin{array}{l}\text { Extra-object depen- } \\
\text { dence }\end{array}$ & No & No & Yes & Yes / No & Yes \\
\hline $\begin{array}{l}\text { Type of logic con- } \\
\text { tained in object }\end{array}$ & (Not applicable) & $\begin{array}{l}\text { None, or answer sheet- } \\
\text { based item scoring }\end{array}$ & $\begin{array}{l}\text { None, or domain- } \\
\text { specific instructional } \\
\text { and assessment }\end{array}$ & $\begin{array}{c}\text { Domain-specific } \\
\text { presentation strate- } \\
\text { gies }\end{array}$ & $\begin{array}{l}\text { Domain-independent } \\
\text { presentation, instruc- } \\
\text { tional, and assessment }\end{array}$ \\
\hline inter-contextual reuse & High & Medium & Low & High & High \\
\hline intra-contextual reuse & Low & Low & Medium & High & High \\
\hline
\end{tabular}

Table 1 is a matrix between the type of learning object and the characteristics of that learning object. Wiley (2000) defines the characteristics as:

- Number of elements combined - Describes the number of individual elements combined in order to make the learning object. 
- Type of objects contained - Describes the type of learning objects that may be combined to form a new learning object.

- Reusable component objects - Describes whether or not a learning object's constituent objects may be individually accessed and reused in new learning contexts.

- Common function - Describes the manner in which the learning object type is generally used.

- Extra-object dependence - Describes whether the learning object needs information about learning objects other than itself.

- Type of logic contained in object- Describes the common function of algorithms and procedures within the learning object.

- Potential for inter-contextual reuse - Describes the number of different learning contexts in which the learning object might be used, that is, the object's potential for reuse in different content areas or domains.

- Potential for intra-contextual reuse - Describes the number of times the learning object might be reused within the same content area or domain.

Wiley (2000) suggests these characteristics are critical attributes and are stable across environmentally disparate instances. The purpose of the taxonomy is to differentiate possible types of learning objects available. This taxonomy is not comprehensive in that it includes only learning object types that facilitate high degrees of reuse. This taxonomy also defines the granular nature of learning objects with respect to generative learning theory. For instance, the generativeinstructional learning object allows the learner to interact with learning material in a learning environment. Other taxonomies for learning object have been presented. Churchill (2007) defined six learning objects: presentation, practice, simulation, conceptual models, information and contextual representation objects. Taxonomies are also specified in vendor specific software packages using learning objects.

\section{Learning Objects: A Paradigm Shift}

The notion of learning objects is problematic for traditional education systems. Contemporary learning is moving away from the notion of learning settings being comprised of pages of text and classrooms, to more deliberately planned learning designs, learning tasks and processes structured in deliberate ways (Oliver, 2001). Oliver (2001) states that in previous settings instructional design had focused on developing pathways for learners through learning content, whereas in contemporary settings the designs are now focusing on providing learning activities that bring about planned learning outcomes.

Downes (2003) discusses how courses are the primary unit of delivery of education in today's education systems. However, Downes believes that courses themselves are not suitable candidates for sharing educational content. Therefore, it should come as no surprise that there is very little sharing of educational resources, even online resources, despite the tremendous cost savings. The main theoretical benefit, again, of sharing educational content is economic. The introduction of learning objects in education requires a paradigm shift from no sharing learning environments to learning environments where information can be shared.

\section{Learning Object Systems: From Theory to Reality}

Thought-leaders in the instructional technology community have begun to wrestle with mapping sound instructional principles to the technical attributes of learning object systems for education 
and training purposes. Much work is being done in the development of learning object systems. This section will describe the three primary components of learning object systems, but will first discuss the stakeholders in a learning object system and the open standard models being adopted for the implementation of learning object systems.

\section{Learning Object Stakeholders}

A learning object system has three primary stakeholders: learners, authors and instructional designers, and developers. This section will describe the roles each of the stakeholders plays in the learning object process. It is important to note that depending on the context, there may be more stakeholders in a learning object system.

- Learners - The learners are the primary users of the learning object systems (Lowe et. al., 2009). Learners issue requests to the learning object systems to gather information about specific content. Generally, the learning objects are designed to suit the needs of many different learning styles. Learning styles represent tendencies and general preferences, and different contexts often invoke different preferences. Nonetheless, learning objects can offer learners ideas, concepts, and information in a variety of forms that will likely benefit more learners than relying on a single presentational form.

- Authors and Instructional Designers - Learning object authors are those that create learning objects for specific learning objectives. In education systems, learning authors are generally faculty in varying educational domains with the expertise to develop learning objects that can be traced to specific learning objectives. Instructional designers, which in some cases are also authors, combine and sequence learning objects to create either larger learning objects or to create high-level instructional components, such as courses, lessons, websites, or books (Longmire, 2001). The instructional designer would also be a teacher utilizing learning objects in a classroom. Instructional designers deliver learning objects through instruction.

- Learning Object Developers - The developers of learning objects are those that satisfy the technical requirements of a learning object system by designing, developing, and maintaining useful software applications for learning object systems (Polsani, 2003). Since the developers are also given the task of maintaining the learning object systems, they also represent the technical administrators of the learning object systems. The developers are given the task of gathering the requirements of a learning object system and conforming to specifications provided by standards organizations such as IEEE.

These are the primary stakeholders in a learning object system; however, there are potentially more stakeholders in a learning object system. For instance, if an organization, such as Cisco, implements a learning object system for training purposes within its organization, then the learners become the employees being trained with the system, the authors and instructional designers become the training department within the organization, and the developers are an in-house Information Technology (IT) department, an external IT service provider, or both. However, in this context, the managers would also play a critical role in the system's development. Managers would look specifically at the costs and benefits of such a system and aid in its direction.

The growing interest in learning objects has given rise to many new organizations, stakeholders, and bodies of literature. In essence, learning objects have created a new economy. The learning object economy refers to all the individuals, groups, consortiums, standards and specifications bodies, organizations, education jurisdictions, and government agencies that are involved in creating learning object content and the hardware, software, and networking systems that support the metadata and learning object databases. 


\section{$X M L$ and Open Standards}

The instructional characteristics of learning object systems provide a set of requirements for the design of learning object systems. The standards should be reusable, accessible, interoperable, and adaptable. Accessibility and interoperability of learning objects is technically achieved using the Extensible Markup Language (XML) over the Hypertext transfer protocol (HTTP). This has become the established transportation protocol to share learning objects in a distributed environment (Skår, Heiberg, \& Kongsli, 2003). These standards conform to the generative and constructive learning theories and map to the instructional characteristics found in the Wiley taxonomy.

Many different open standards have been established for the structure of learning objects; such as, Learning Object Metadata (LOM) standard produced by the IEEE 1484.12.1 (IEEE, 2002). The IEEE standard approved December 10, 2002 defines a meta-model to categorize and describe learning objects. By conforming to these standards using XML, learning resources from different providers are available in a consistent format for sharing, searching, and indexing on the web. The LOM standard includes some sixty plus fields to describe a learning object. Many of these fields directly relate to Wiley's learning object taxonomy.

Another popular open standard is the Sharable Content Object Reference Model (SCORM), an Advanced Distributed Learning initiative (Bohl, Schellhase, Sengler, \& Winand, 2002). The SCORM standard is commonly used for the implementation of interoperable learning management systems. A definition and description of a learning management system is provided in the following section. The SCORM model follows a similar standard to the LOM model with respect to the required fields. Bohl et al. (2002) believe that the SCORM standard has become the standard dominating the market.

\section{Learning Object Authoring Tool}

The utilization of a robust authoring tool is the first step in developing a learning object system. Universities have pioneered the creation of authoring tools for next generation learning environments demonstrating diverse pedagogical approaches (Spohrer, Sumner, \& Shum, 1998). The IT industry has also equipped computers with robust authoring tools in record-breaking numbers. Authorware and Lectora are especially popular in e-learning environments. There are numerous other proprietary authoring tools available. These tools enable authors to create dynamic interactive instructional content for learners.

Authors of course content develop learning objects using these authoring tools. These tools generally follow a standard, such as SCORM. An authoring tool is similar to a computer assisted software environment. The authors are actually creating two data sets when creating learning objects: the learning object content, and the learning object metadata. After the learning objects are created, they are inserted into a learning object repository.

\section{Learning Object Repository}

The core of a learning object system is a central repository (database) containing hundreds to thousands of individual learning objects. The information stored in these repositories would be accessed by an array of applications and end users, including learners and the instructional designers. Attached to each learning object in the database is metadata. The metadata includes subject-specific information by conforming to the open standards. 


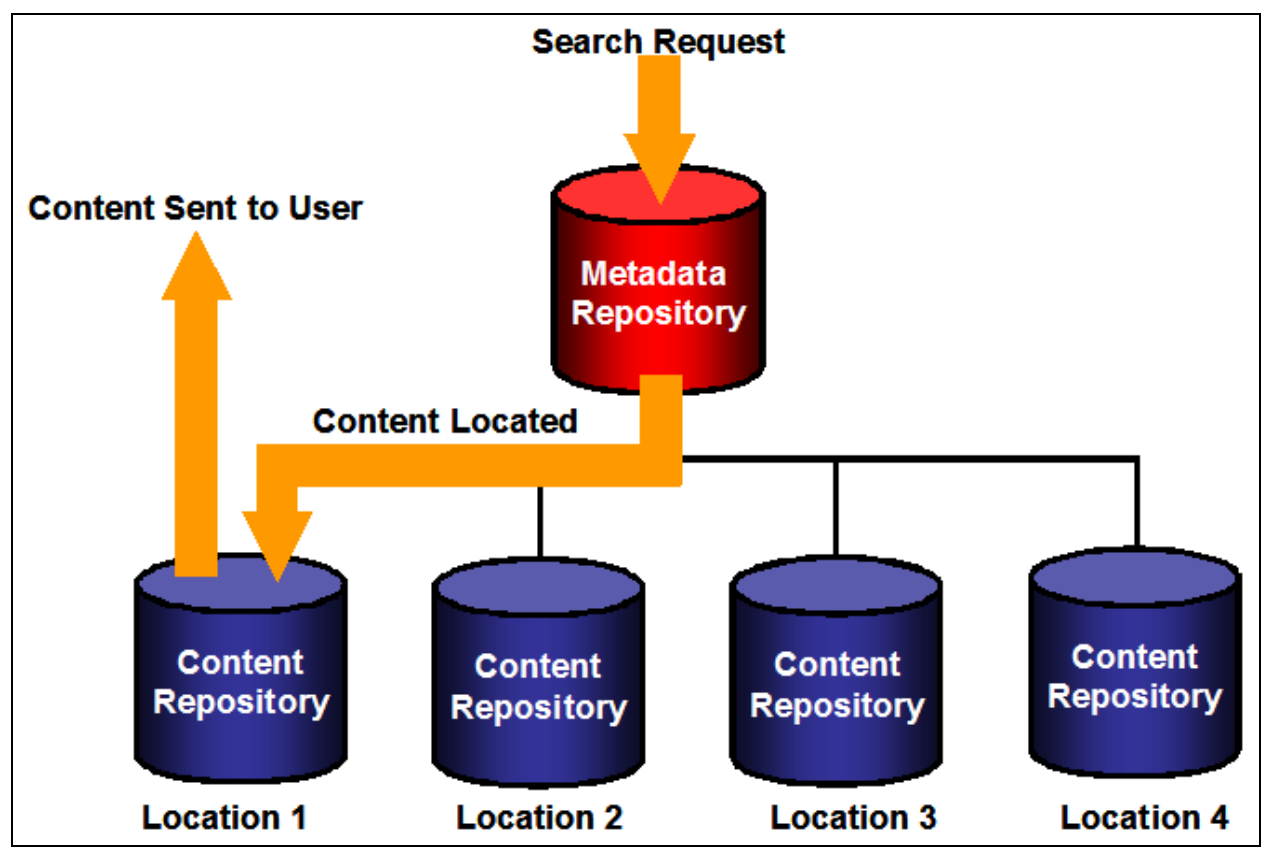

Figure 1. Learning Object Repository - Centralized Metadata.

Figure 1 shows a simplified view of the process of retrieving a learning object from a repository. It is evident in the exhibit that the content of the repository can be geographically dispersed. A search request is sent to the metadata repository, which contains information about each of the learning objects in the repository and subsequently requests the information from the specific content repository.

Two core models for learning object repositories exist. The most common form is a centralized form in which the learning object metadata is located on a single server (Downes, 2003). This type of architecture is evident in Figure 1 where the metadata is stored on one server and the content is stored on many others. An alternative model is the distributed learning object model, in which the learning object metadata is contained in a number of connected servers. Distributed learning object repositories typically employ a peer-to-peer architecture to allow any number of servers to communicate with each other (Downes, 2003).

Learning object systems around the world could access this metadata to form its own complete set of learning resources. The learning repository will retrieve only that metadata relevant to the search request; therefore, it is filtered metadata that will be accessed by the learning systems. Some of the more common learning object repositories include: the University of Wisconsin Online Resource Center (WORC), Multimedia Educational Resource for Learning and Online Teaching (MERLOT), and the Apple Learning Exchange (ALE).

\section{Learning Object Management System}

As evident by the discussion till now, learning objects are typically small. However, most educational institutions deliver larger chunks of instruction - courses (Downes, 2003). Using a Learning Management System (LMS), an instructional designer defines major features of the course: its topic area, or perhaps its grade level. The author then instructs the LMS to search through the learning object repository for relevant resources. From the search results, the author may review a learning object or select it for inclusion in the course. The LMS retrieves the object metadata from the repository and inserts it into the course package. The LMS automatically adds institution-specific formatting and prepares the package for delivery. 
While an instructional designer could locate and assemble learning objects by hand, it would be tedious and unproductive. The basic LMS performs two major functions: it provides instructional designers with a means of locating learning objects, and it assembles them into standard compliant learning units (Downes, 2003). Although many types of LMSs are available, the enhanced LMS will contain four essential features: an authoring application similar to the computer assisted software environment (CASE), a collection of learning objects described above, a means of sending the completed course to a delivery system (called a delivery interface), and administration tools (Downes, 2003). The LMS systems have been enhanced to include additional features, such as intelligent tutoring or adaptive learning components for learners (Stoilescu, 2008). Therefore, some LMS provide services directly to a learner. The enhanced LMS, sometimes referred to as a Learning Content Management System, is a hybrid system that contains all the essential elements of a learning object system.

Figure 2 depicts an enhanced LMS with respect to a learning object repository, the delivery device, and the learner. This diagram shows that a learning management system is attached to a learning object repository which is generally a database consisting of the metadata and content data. The LMS uses the data in the learning object repository to "deliver" a type of instruction to a learner. Therefore, an enhanced LMS will provide direct services to the learner. The learner views this information using a device, which is generally a web browser, such as Internet Explorer or Firefox. An important note is that the learner can access the learning content using many different devices. Some of these devices require mobile technology, such as a Personal Digital Assistant (PDA), or a wireless smart phone (Churchill \& Hedberg, 2008).

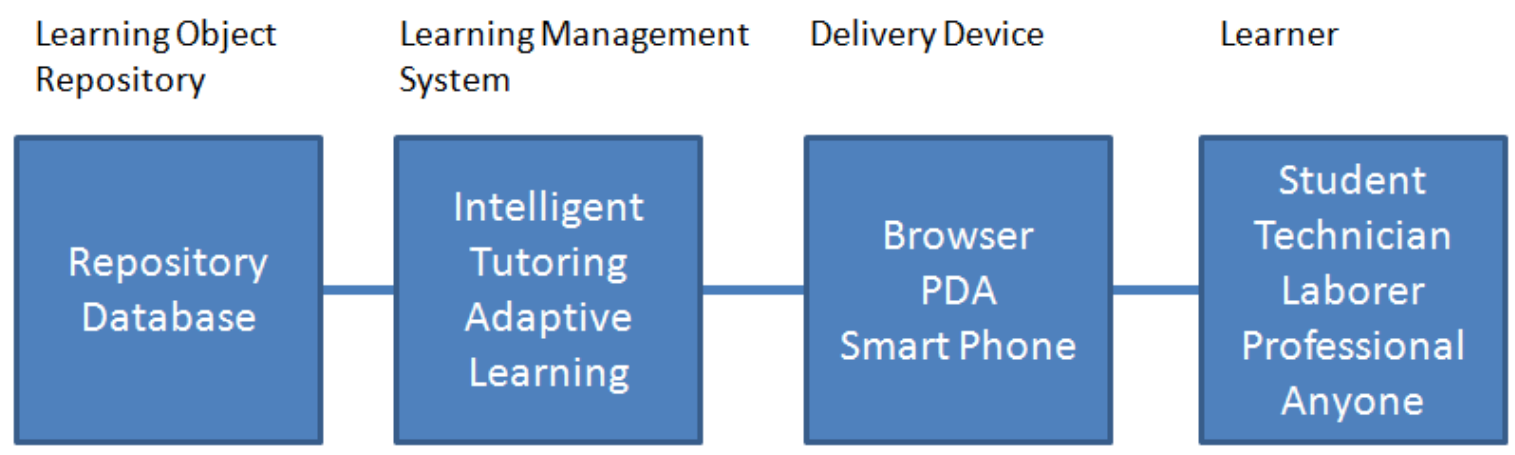

Figure 2. Enhanced Learning Management System.

\section{Holistic Model of a Learning Object System}

Figure 3 provides a holistic picture of a generic learning object system with respect to each of the stakeholders and their role in the system. As evident by the diagram, the authors use an authoring tool to develop learning objects and insert them into the repository. After creating the learning objects, instructional designers use the learning objects to deliver instruction to learners. Authors can also update learning objects directly through the learning object repository or by using the authoring tool.

Learners experience learning objects though a learning management system via prescriptive learning, intelligent tutors, or perhaps through adaptive learning. Learners could also experience learning objects via instructional designers delivering lectures, hands on exercises, or perhaps training session for an organization. This is the environment where a learner is an active participant in the instructional experience, constructing knowledge through relating information in the instructional environment to his or her previous experiences and prior knowledge. 


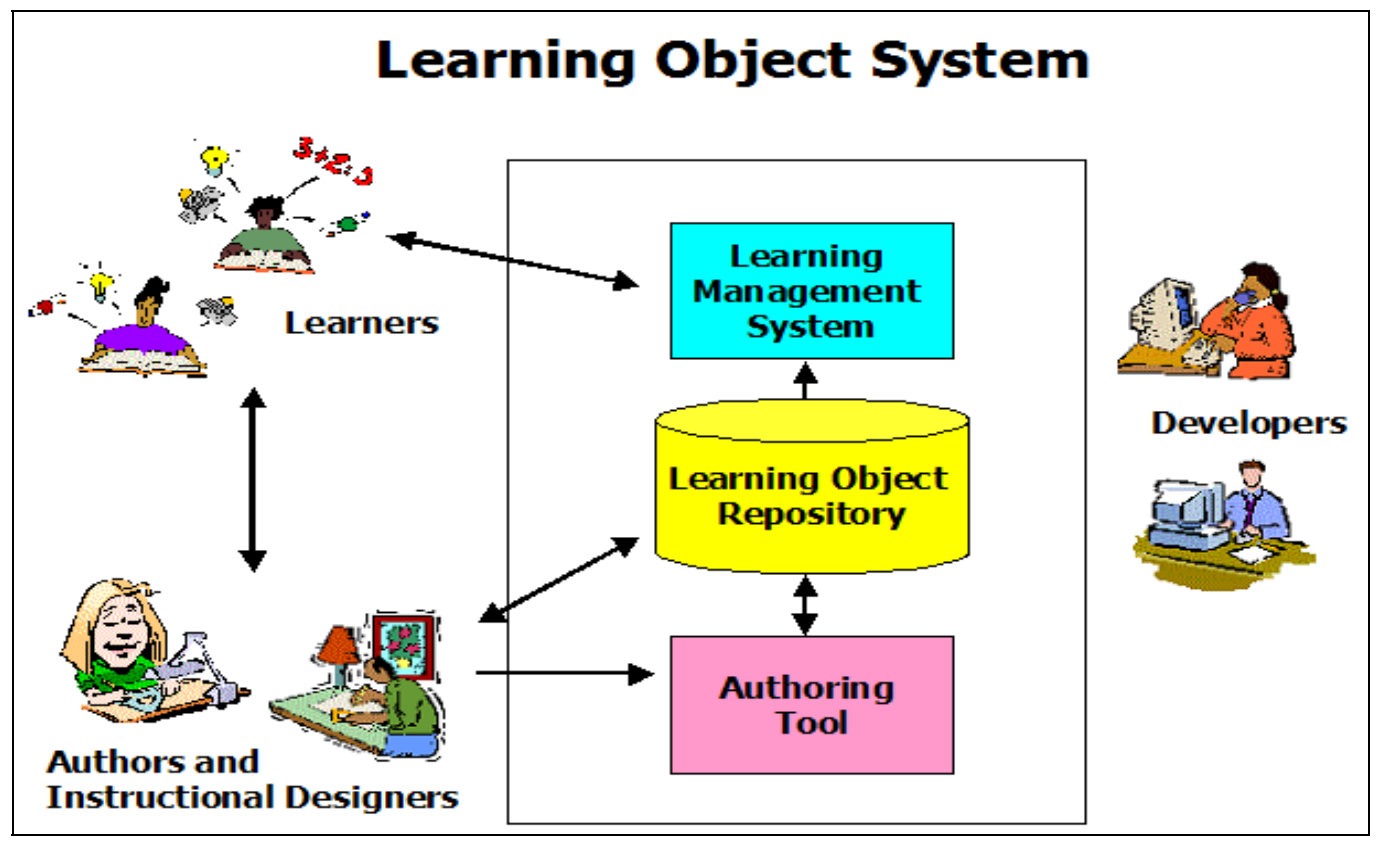

Figure 3. Generic Learning Object System.

The final stakeholders in the system are the developers. The developers of learning objects are those that satisfy the technical requirements of a learning object system by designing, developing, and maintaining useful software applications for learning object systems. The developers could be an in-house IT department, an external IT service provider, or both.

\section{Learning Object Environment}

The decision to utilize a learning object system is largely dependent on the type of learning environment. Three of the major different organizational contexts for the use of learning objects are the university, corporation, and military establishments. Collis and Strijker (2004) say that the use of learning objects will differ based on the environment in which the learning objects reside. A university setting is based on instructor-delivered courses with lectures. This approach remains the norm, but web-based course-management systems, such as Blackboard, are routinely used to support the courses throughout their cycles (Boer, 2002).

A corporate environment typically uses two different delivery forms: a classroom with an instructor or an e-learning environment without an instructor (Collis \& Strijker, 2004). A mixture of these two forms which is termed as "blended learning" is now appearing, but unlike the university setting, a course-management system is not typically used. Instead an LMS may be employed to deliver and track the e-learning component (Collis \& Strijker, 2004). The classroom-portion of the blend generally does not make use of learning objects or electronic delivery systems unless instructional designers use learning objects for preparation. A military setting uses a classroom setting or computer-based training, but typically there is no combination of the two in a single course (Collis \& Strijker, 2004).

Collis and Strijker (2004) believe that the way in which learning objects are used and the strategy depends on the organizational context. Collis and Strijker say specific questions need to be addressed to adopt a learning object system: "What is in it for the organization? Is there an organizational strategy? What is the reason for implementing a reuse strategy in the organization?" 


\section{Potential Benefits of a Learning Objects System}

Learning object systems provide many benefits to all the stakeholders. Wagner (2002) writes about a number of the benefits derived from a learning object system:

- Increased value of content - The value of content is increased every time it is reused. This is reflected in cost savings by avoiding new design and production efforts. Selling learning objects or providing them to partners may offer additional revenue generation opportunities.

- Improved content flexibility - When content is captured in an object format, it can be reused much more easily than material that has to be rewritten for each new context or application.

- Improved updating, searching, and content management - Metadata tags describing various attributes of a learning object help organize, identify, and locate relevant content. This improves searching, facilitates management and maintenance, and helps filter and select the relevant content for a given purpose.

- Content Customization - The learning object approach enables a just-in-time approach to customization by allowing designers to select, assemble, and rearrange content according to stakeholder needs.

South and Monson (2000) identify a more detailed inspection of the benefits of learning objects. They identify the "ilities" which are:

- Durability - The retention of integrity of the learning content over time.

- Interoperability - The open structure of the objects allowing them to be used on a multitude of computer platforms

- Accessibility - The ease of retrieval.

- Reusability - The fact that any given object can be used in a variety of different learning contexts.

- Discoverability - The scalability of each of the objects allowing the learner to be active in the learning process rather than a passive recipient of information.

- Extensibility - The flexibility one has to develop coding definitions to accommodate the many different ways that any object can be classified.

- Affordability - The cost effectiveness of the learning objects in that once they are developed and archived they can be used repeatedly and also reduce development time.

- Manageability - The ease with which learning objects can be stored in repositories and later retrieved based on metadata.

It should not be surprising that most of the benefits, as discussed by South and Monson (2000) and Wagner (2002), derived from learning object systems directly relate to the learning theories presented earlier in the discussion. The notions of adaptability, granularity, reusability, interoperability, and accessibility are the pillars for learning object systems. These pillars lead to many potential benefits provided by a learning objects system.

\section{Potential Drawbacks of a Learning Objects System}

A learning object system is not the silver bullet to e-learning needs. Parish describes many of the problems with learning objects and learning object systems. Parish (2004) writes: 
- Lacking a clear definition - The learning object economy has difficulty defining a learning object. Without a clear picture of what a learning object is, it becomes extremely difficult to use them.

- Intellectual property rights - The question of ownership is also a problem. After an author creates a learning object and publishes it, the question of ownership arises.

- Language and geographical differences - A learning object might be useful in the United States, but that would not make it useful in India.

- Lack of knowledge and understanding - Many faculty members do not even know that the learning object systems exist.

- Difficult technical specification - The metadata data specifications, such as SCORM, require seventy plus fields for a single learning object.

These aforementioned topics are just some of the many difficulties relating to learning objects. Currently, there is no clear financial evidence to determine whether learning objects live up to their promise of financial savings or increases in productivity. All the material in the bodies of literature is still theoretical in nature. Other problems also exist. For instance, in the case study of the Wisconsin Online Resource Center discussed below, many challenges are presented that are difficult to overcome in the implementation of a learning object system. There is also the possibility that the learners might not learn from the available learning objects. Furthermore, there are steep costs associated with retooling, retraining, and recreating learning objects from other instructional content. Learning objects are not a perfect solution.

\section{Learning Object Strategy}

An e-Learning strategy is concerned with how information and communication technologies are utilized to facilitate learning - as over the Internet. The introduction of learning objects into the eLearning community presents an unanswered question. Are learning object systems consistent with e-learning strategies? Vossen and Jaeschke (2003) suggest that learning objects are the uniform foundation for e-Learning platforms. A learning object system, as described by Vossen and Jaeschke, is the stable technical and theoretical platform for e-learning. Two well-known learning object systems are frequently discussed in scholarly literature: Cisco's learning object system, and the Wisconsin Online Resource Center. Each of these learning object systems is consistent with the organization's e-learning strategy. A brief case study of each of these systems is presented. These case studies attest to learning object systems being implemented on both a micro and macro scale and, also, to a learning object system being consistent with an e-learning strategy. Furthermore, these case studies highlight the issue that there are significant costs associated with the implementation of a learning object system. Changing to a learning object system from a different system involves retooling and retraining costs, and costs for recreating content.

\section{Case Study 1: Cisco's Learning Object System}

Cisco's implementation of a learning object system is often discussed in scholarly journals as being consistent with an e-learning strategy. Cisco Systems transformed its instructor-led Career Certification courses into an e-learning format to better streamline lessons, allow thousands of employees to learn at their own pace, and arm its closest learning partners with reusable learning objects they could repurpose into customized course offerings (Maddocks, 2002). In early 2000, Cisco CEO John Chambers said that he wanted Cisco to be "the" e-learning company, and he was looking to its Internet Learning Solutions Group to deliver that vision. The Internet Learning Solutions Group decided to implement a reusable learning object strategy to answer his call (Maddocks, 2002). 
Adopting a learning object strategy coupled with using an authoring tool known as OutStart's Evolution, Cisco was able to redesign and rewrite all eight of its certification courses and create one content set (Maddock, 2002). This ensured that courses were consistent in instructional design and technical accuracy. Cisco's learning solution partners embraced a blended approach and now provides a package of offerings for each course: traditional classroom training, live virtual training, or self-paced e-learning. Partners also can take source content and create customized solutions for their customers by combining a variety of learning objects into new offerings. Cisco reports that although many of its learning partners were reluctant to move to an e-learning format for delivery, they soon came to realize that their internal classroom instructors could benefit from a new approach.

Cisco's vision depended heavily on partners. By developing a learning object system that combined OutStart's Evolution, Cisco's licensed LMS, and internal custom applications, Cisco is achieving its goal: to enable all employees to use e-learning to access on-demand, personalized training, in the media of their choice, and to improve job performance. Cisco reports that the benefits to the learning object strategy are clear. Previously it could take nearly nine months to develop a course that now takes eight to twelve weeks to develop and execute. From a financial perspective, the capability to reuse content and a reduction in content development time, Cisco anticipates a five hundred percent return on investment (Maddock, 2002). For example, Cisco recently developed a course in half the time and budget by reusing learning objects, and over the past year, developed more than 130 courses, 2,500 lessons, and 20,000 reusable learning objects (Maddock, 2002).

Cisco also attests to the use of learning objects in making prescriptive learning a reality stating there has been a collective attitude change among employees who now embrace e-learning as a critical career development tool (Maddock, 2002). Cisco now offers an assessment that prescribes the learning objects people need to achieve the desired performance. From a learning perspective, what Cisco cares about is performance, and performance measurement is a core strategy.

\section{Case Study 2: Wisconsin Online Resource Center}

The Wisconsin Online Resource Center is one of the largest and most successful implementations of a learning object system. The process of developing this system provides for an interesting case study. The Fund for the Improvement of Post-Secondary Education provided money through its brand new Learning Anywhere Anytime Partnership for a 3-year proposal to develop an online resource center of learning objects for nine courses called the General Education "core" in the Wisconsin Technical College System (Chitwood et al., 2000).

The e-learning strategy was to develop a learning object system based on new way of thinking in the field of curriculum development and course design. This new way of thinking would require that educators focus on learning and the learner by creating self-contained, reusable, high-quality learning chunks that could be combined and recombined in courses, learning activities and experiences, and assessments that meet a learner's immediate needs (Chitwood et al., 2000).

Chitwood et al. (2000) describe the implementation of the system as a set of challenges. The first challenge was taking the idea and mapping it to a written project proposal. This challenge required the core team working on the project to gather support from sixteen other state districts. The next challenge required for all sixteen districts to meet (including technical staff, faculty teaching the nine courses, and administrators) and commit to the implementation of the project. After a final commitment was made from all parties involved, the project went to the next level.

The next set challenges were human resource issues. The project required the commitment of faculty for the authoring of the learning objects, and a technical staff to implement the system. Furthermore, a concrete understanding of learning objects was required for the development team to 
understand what had to be done. The development team needed to train themselves in learning object theory. Other challenges relating the bureaucracy of a statewide education system and intellectual property rights were also encountered (Chitwood et al., 2000).

The resultant is a statewide system used by sixteen different institutions for creating, capturing, and delivering learning objects. Faculty authors from throughout the system create learning objects for each competency within the General Education (WORC, 2004). Individual instructors then have the option to pick and choose from a vast assortment of the learning objects to customize their online courses and their on-campus courses for their students. The initial proposal was funded \$1.6 million over a three-year duration. The project, now fully functional, only reports spending $\$ 800$ thousand on the implementation of the Wisconsin Online Resource Center (WORC, 2004).

\section{Closing Remarks}

This paper has documented the theory behind learning objects and the implementation and use of learning object systems. The premises of the constructivist and generativist learning theories are discussed to map the principles of these theories to the implementation of instructionally sound learning object systems. Constructivist and generativist learning theories suggests that learners are not passive recipients of information but active participants in the instructional experience, relating information in the instructional environment to their previous experiences and prior knowledge. These theories trace instructional principles that are evident in learning object systems: accessibility, reusability, adaptability, intolerability, and granularity. As discussed, these pillars are also the primary benefits that learning object systems provide.

At this point, it is necessary to revisit the research question under investigation. How do learning objects improve the delivery of quality education? The answer to the question required an understanding of the theory behind learning objects and the implementation and use of learning object systems because learning objects themselves do not result in improved delivery of educational content. A simple answer is that learning object systems are the vehicles that deliver "quality education." Still, the answer to this question is multifaceted. The benefits of a learning object system improving the delivery of quality education depend on perspective and relate to the perceived benefits of the learning object system.

This paper has documented the types of learning object systems that have evolved in the past fifteen years. Learning object systems continue to evolve; however, most system will include an authoring tool to create learning objects, a repository to store and deliver learning objects, and a LMS to provide learners a complete learning experience. These components are the vehicles that deliver "quality education."

Learning object systems provide an accessible digital forum where learners can easily access learning objects that map to specific learning objectives. The learning objects themselves are easy to access because they are digital and shareable over networks and because they are tagged in XML using a standard such as SCORM or LOM. Using the metadata, learners or instructional designers can do simple searches in a learning object repository to find the desired content.

The granularity of learning objects affords instructional designers and LMSs the ability to supply students with a customized learning experience. Rather than a student relearning competencies they already understand in a course or textbook, a LMS or instructional designer can combine and sequence learning objects that specifically meet a learners needs. The amount of time spent reading or listening to immaterial information is therefore reduced.

Since the learning objects are compliant to a predefined standard, they can be used in varying software applications and platforms that accept the standard - confirming the interoperability of 
learning objects. This provides learners from varying locations using heterogeneous machines access to learning content without the concern of compatibility. Furthermore, it easier to manage instructional content since the learning objects are stored in repositories and based on metadata. A learning object system streamlines instructional content.

The true power behind a learning object is that different learners can reuse it many times. Learning objects are stored in database systems where they can be easily maintained and revised if necessary. When a book becomes out of date, a new version is released, costing learners more money. Using a learning object strategy, authors can easily update a learning object in a database, and it does not require a new version (versioning) to be published because a learner can access the learning object on demand.

From a financial perspective, learning object systems promise great cost savings by streamlining educational content, which leads to an increase in productivity. Both educational institutions and learners can realize these cost savings. An educational institution would reduce the costs of creating and managing instructional content, and therefore the reduced costs would pass to the consumers of their services - the learners. However, there is still lacking literature validating the costs and benefits of a learning object system. This is primarily due to learning objects being a newer idea. Few systems have been implemented and measured.

The many theoretical benefits provided by a learning object system make it a viable e-learning solution for many organizations. Learning object systems improve the delivery of quality education by providing many benefits to all the stakeholders in the system whether they are financial or operational in nature. However, many unresolved issues surrounding learning object systems need to be addressed.

\section{Unresolved Issues}

Much work is required by the learning object economy to fully realize all the benefits of a learning object strategy. This is most obvious in the deficiency of a clear definition of learning object. Implementation of a learning object strategy is nearly impossible without a clear picture. The intellectual property rights of learning objects also need to be clear if organizations plan to share the content. For instance, if the repository developers are given the ownership of a learning object created by a specific author, can the repository developers sell the learning object? If so, are royalties due to the author? Many unanswered questions relating to intellectual property rights need answers before a community or organization will choose to implement a learning object strategy.

The learning object economy also needs to address the language barriers. Clearly, educational content in an English speaking country would be of no value to a Spanish speaking country unless some feature to translate the content is available. In a global economy, communication barriers become major hurdles. Another problem that needs to be addressed is the taxing technical requirements posed by the metadata data specifications. If learning object authors are overwhelmed in technical detail, it is likely that less educational content will be developed. However, some authoring tools mitigate the taxing technical requirements of the open standards.

The two most important unresolved issues are the lack of interest and understanding, and the lack of evidence supporting the financial benefits of learning object systems. The problem of apathy in the education community regarding learning objects is attributable mostly to ignorance. Educators are not aware that learning object repositories even exist. If educators are not aware they exist, then educators will not be able to contribute to or use the systems to improve the delivery of quality education. The key solution to this problem is to involve and educate educators on the benefits of learning objects. 
Finally, work needs to be done to financially justify the benefits of a learning object system. All the evidence presented is theoretical in nature or is not validated in a reliable source. Until financial justification is validated, most organizations will not adopt learning object systems. Much of this problem is attributable to the fact the learning object systems have just started to be developed by organizations, and measurements have not been taken or published (Kay, \& Knaack, 2009). However, this information is crucial for making an investment into a newer endeavor.

With all the considerations outlined, this paper advocates the adoption of a learning object strategy for varying organizations. This assertion is predicated on the organization clearly defining goals and expectations of the system because the use of the system will differ based on the organization. This assertion is also based on an organization weighting the costs and benefits of such a strategy.

\section{Organizational Implications}

Organizations with learning needs should consider adopting a learning object strategy. Cisco's goal to become a leader in e-learning strategy and its implementation of an e-learning system will provide it with many benefits in the future if carefully managed. The decision, however, of an organization to adopt a learning object strategy for their e-learning needs is a difficult one. The benefits of choosing such a strategy are numerous and have been outlined. Managing learning resources collectively as an organization using a learning object system has implications to an organization. Changing to a learning object system from a different system involves retooling and retraining. Furthermore, there is a cost of converting existing content into learning objects may be significant

The decision to implement a learning object strategy is a large organizational commitment that requires the support of senior management, as shown in Cisco's implementation. Collis and Strijker (2004) suggested that the nature of the organization will ultimately affect the outcome of how learning objects are used in that organization. What is in it for the organization? The use of a common resource makes it easier to take up new opportunities, and the benefits of such a strategy should be clearly defined to maximize the benefits of such a system. South and Monson's (2000) "ilities" for learning objects promise significant gains to an organization. These "ilities" coupled with shorter development times and theoretical cost reductions would surely benefit an organization. However, the cost to develop such a system is a significant investment. Therefore it is incumbent upon organizations to do a cost and benefit analysis. As stated earlier, clearly defined goals and expectations must be defined because the use of such systems varies between organizations.

\section{Individual Implications}

The decision of an organization to adopt a learning object system for their learning needs will also impact individuals (learner, educator). With the advent of learning object systems educators can use a common process for storing their learning resources using authoring tools and learning object repositories, but now deliver them in any way they choose. Furthermore, educators know their instructional content is securely stored and centrally managed. Educators can improve the quality of teaching and training simply by having easy access to the best resources. However, if educators do not utilize these resources, than no real benefits will be gained.

To a learner, learning object systems provide a plethora of benefits since they are the ultimate stakeholders of the systems. Learners can access customized content on demand. Learners and educators, however, will both have to adjust to new learning environments that are based on the generative and constructive learning theories - a shift in paradigm. 


\section{References}

Bannan-Ritland, B., Dabbagh, N., \& Murphy, K. (2002). Learning object systems as constructivist learning environments: Related assumptions, theories and applications. In D.A. Wiley (Ed.), The instructional use of learning objects. Bloomington, IN.

Boer, W.F. (2002). ICT in teaching and learning: Part of a blend. In B. Collis, \& M van der Wende (Eds.). Models of technology and change in higher education: An international comparative survey on the current and future use of ICT in higher education. Enschede: CHEPS.

Bohl, O., Schellhase, J., Sengler, R., \& Winand, U., (2002). The Sharable Content Object Reference Model (SCORM) - A critical review. Proceedings of the International Conference on Computers in Education.

Boyle, T. (2002). Design principles for authoring dynamic, reusable learning objects. Australian Journal of Educational Technology, 19(1), 46-58.

Chitwood, K., May, C., Bunnow, D., \& Langan, T. (2000). Battle stories from the field: Wisconsin online resource center learning objects project. In D. A. Wiley (Ed.), The instructional use of learning objects [Online Version]. Retrieved June 5, 2009, from the World Wide Web: http://reusability.org/read/chapters/chitwood.doc.

Churchill, D. (2007). Towards a useful classification of learning objects. Educational Technology Research and Development, 55(5), 479-497.

Churchill, D., \& Hedberg, J. (2008). Learning object design considerations for small-screen handheld devices. Computers \& Education, 50(3), 881-893.

Collis, B., \& Strijker, A. (2004). Technology and human issues in reusing learning objects. Journal of Interactive Media in Education, (4). Special Issue on the Educational Semantic Web. Retrieved on June 14, 2010 from http://www-jime.open.ac.uk/2004/4/

Degen, B. (2001). Capitalizing on the learning object economy: The strategic benefits of standard learning objects. Learning Objects Network, Inc. Retrieved June 5, 2009, from the World Wide Web: http://www.learningobjectsnetwork.com/resources/

Downes, S. (2003). Design and reusability of learning objects in an academic context: A new economy of education? Journal of the United States Distance Learning Association, 17(1).

Duffy, T.M., \& Cunningham, D. J. (1996). Constructivism: Implications for the design and delivery of instruction. In D. Jonassen (Ed.), Handbook of research for educational communications and technology (pp. 170-198). New York, NY: Macmillan.

Grabowski, B. L. (1996). Generative learning: Past, present \& future. In D. H. Jonassen (Ed.), Handbook of research for educational communications and technology (pp. 897-913). New York: Simon Schuster, McMillan.

Hodgins, H. W. (2002). The future of learning objects. Proceedings of the 2002 eTEE Conference, 76-82.

IEEE (2002): IEEE Draft Standard for Learning Object Metadata, Approved specifications of the IEEE, 1484.12.1-2002, 44.

IMS (2003, September 5). IMS Global Learning Consortium Background. Retrieved June 5, 2009, from the World Wide Web: http://www.imsglobal.org/background.cfm.

Kay, R. H., \& Knaack, L. (2009). Assessing learning, quality and engagement in learning objects: The Learning Object Evaluation Scale for Students (LOES-S). Educational Technology Research and Development, 57(2), 147-168.

Learnativity. (2004). Some history behind current learning standards initiatives and some updates. (2001, December 17). Retrieved June 5, 2004, from http://www.learnativity.com/lalo.html

Longmire, W. (2001). A primer on learning objects. Learning Circuits. Retrieved on June 14, 2010 from: http://www.astd.org/LC/2000/0300_longmire.htm 
Lowe, K., Lee, L., Schibeci, R., Cummings, R., Phillips, R., \& Lake, D. (2009). Learning objects and engagement of students in Australian and New Zealand schools. British Journal of Educational Technology, 41(2), $227-241$.

Maddocks, P. (2002). Case study: Cisco systems ventures into the land of reusability. Learning Circuits: ASTD's Source for E-Learning. Retrieved June 5, 2004, from http://www.learningcircuits.org/2002/mar2002/maddocks.html

Merrill, M. D. (1999). Instructional transaction theory (ITT): Instructional design based on knowledge objects. In C. M. Reigeluth (Ed.), Instructional design theories and models: A new paradigm of instructional theory (pp. 397-424). Hillsdale, NJ: Lawrence Erlbaum Associates.

Oliver, R. (2001). Learning objects: supporting flexible delivery of flexible learning. Meeting at the crossroads: Proceedings of ASCILITE, 453-460.

Parrish, P. E., (2004). The trouble with learning objects. Educational Technology, Research and Development, 52(1), 49-67.

Polsani, P. R. (2003). Use and abuse of reusable learning objects. Journal of Digital Information, 3(4). Retrieved on June 14, 2009 from: http://journals.tdl.org/jodi/rt/printerFriendly/89/88

Skår, L.A., Heiberg T., \& Kongsli V. (2003). Reuse learning objects through LOM and XML. Association of Computing Machinery: Conference on Object Oriented Programming Systems Languages and Applications, 78-79.

South, J. B. \& Monson, D. W. (2000). A university-wide system for creating, capturing, and delivering learning objects. In D. A. Wiley (Ed.), The instructional use of learning objects [Online Version]. Retrieved June 5, 2009 from http://reusability.org/read/chapters/south.doc

Spohrer, J., Sumner, T., \& Shum, S. B., (1998). Educational authoring tools and the educational object economy: Introduction to this special issue from the East/West group. Journal of Interactive Media in Education, 10, 1-14.

Stoilescu, D. (2008). Modalities of using learning objects for intelligent agents in learning. Interdisciplinary Journal of E-Learning and Learning Objects, 4, 49 - 64. Retrieved from http://www.ijello.org/Volume4/IJELLOv4p049-064Stoilescu394.pdf

Wagner, E. D. (2002). The new frontier of learning object design. The E-Learning Developers Journal, 1-7.

Wiley, D. A. (2000). Connecting learning objects to instructional design theory: A definition, a metaphor, and a taxonomy. In D. A. Wiley (Ed.), The instructional use of learning objects [Online Version]. Retrieved June 5, 2004, from http://reusability.org/read/chapters/wiley.doc

WORC. (2004, December 17). About the Wisconsin Online Resource Center Retrieved June 5, 2009, from the http://www.wisc-online.com/index.htm

Vossen, G. \& Jaeschke, P. (2003). Learning objects as a uniform foundation for eLearning platforms. Proceedings of the Seventeenth International Database Engineering and Applications Symposium. 


\section{Biography}

Albert D. Ritzhaupt is an Assistant Professor of Educational Technology in the School of

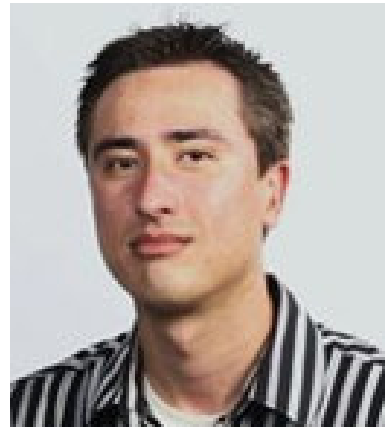

Teaching and Learning at the University of Florida. His primary research areas focus on the development of technology-enhanced instruction, and technology integration in education. His publications have appeared in multiple venues, including the Journal of Computing in Higher Education, Behavior Research Methods, Journal of Educational Computing Research, Computers \& Education, Journal of Digital Learning in Teacher Education, International Review of Research in Open and Distance Learning, Journal of Research on Technology in Education, and Computers in Human Behavior. Ritzhaupt also regularly presents at both national and international conferences. 